The Israeli Journal of Aquaculture IJA.73.2021.1530200, 12 pages

CCBY-NC-ND-4.0 • https://doi.org/10.46989/001c.28425

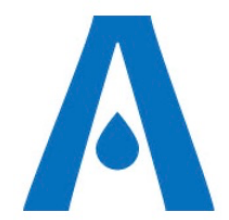

The $I J A$ is a peer-reviewed open-access, electronic journal, freely available without charge to users

Produced by the AquacultureHub non-profit Foundation Sale of $I J A$ papers is strictly forbidden

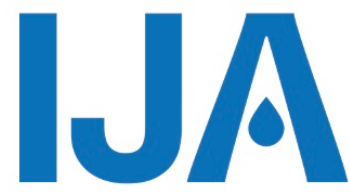

\title{
Effects of Photoperiod, Water temperature, and Exogenous Hormones on Spawning and Plasma gonadal Steroid in Starry Flounder, Platichthys stellatus
}

\author{
Beom Seok Hong ${ }^{1}$, Hyo Bin Lee², Jung Yeol Park', Ji Hye Yoon², \\ Il Young Lee ${ }^{3}$, Han Kyu Lim ${ }^{1,2 *}$ \\ ${ }^{1}$ Department of Marine and Fisheries Resources, Mokpo National University, Muan, \\ Jellanam-do 58554, Republic of Korea \\ 2 Department of Biomedicine, Health \& Life Convergence Sciences, Mokpo national \\ University, Muan, Jellanam-do 58554, Republic of Korea \\ ${ }^{3}$ Marine Seed, Yeosu, Jellanam-do 59777, Republic of Korea
}

Key words: Platichthys stellatus, Photoperiod, Temperature, Maturation, Sex steroid

\begin{abstract}
The sexual maturation and spawning of teleosts are regulated by the external environment and the endocrine system. When the environmental conditions are artificially adjusted at a fish farm, the maturity and spawning of fish can be controlled. In this study, sexual maturation and spawning of the starry flounder, Platichthys stellatus, were artificially induced by adjusting the water temperature and photoperiod at a fish farm to accelerate the species' natural spawning period. One experimental group acted as a control and was exposed to a natural photoperiod and natural water temperature (NPNT). In contrast, another experimental group was exposed to an adjusted environment consisting of a regulated photoperiod and temperature (RPRT). Daylight time was reduced by 10 minutes every 3 days from 13 hours to a duration of 8 hours. The water temperature was first reduced by $1^{\circ} \mathrm{C}$ every day, starting at $22^{\circ} \mathrm{C}$ and ending at $8^{\circ} \mathrm{C}$, and then raised to $10^{\circ} \mathrm{C}$ until the spawning period. Both experimental groups were treated with gonadotropin-releasing hormone analog $(\mathrm{GnRHa})$ pellets to induce ovulation. The results show that when the water temperature and photoperiod were artificially controlled, ovulation could be induced 97 days earlier than the natural spawning. Plasma testosterone levels of RPRT and NPNT tended to increase and then decrease 1-2 months before spawning, and plasma levels of 17a,20ß-dihydroxy-4-pregnen-3-one increased 1-2 months before spawning. The concentration of estradiol-17 $\beta$ (E2) in plasma was not associated with spawning.
\end{abstract}

* Corresponding author. Tel.: +82-61-450-2395, fax: +82-61-452-8875, e-mail: limhk@mokpo.ac.kr 


\section{Introduction}

The endocrine system regulates the reproductive cycle of teleosts, which is affected by environmental factors such as water temperature and photoperiod (Wang et al., 2010). Significantly in temperate seas, environmental characteristics are related to seasons, and fish that inhabit temperate seas have adapted their reproduction cycle to the seasonal changes in their environment. For fish farming, this seasonal breeding periodicity limits the spawning season, often reducing economic benefits. Consequently, many studies have investigated the control of the reproductive cycle of fish by regulating their environment; these results can be applied in the fish farm industry (Wang et al., 2010; Cyr et al., 2018). Photoperiod and water temperature are the most studied environmental factors for controlling artificial maturation and spawning. These two factors can be accelerated, delayed, or induced year-round (Wang et al., 2010; Norberg et al., 2004; Planas \& Chamorro, 2013; Imsland et al., 2019; Lundova et al., 2019; Akhoundian et al., 2020).

Regulating the photoperiod and water temperature can control the rearing environment and the sexual maturation and reproductive cycle of farmed fish. Exogenous hormone treatment effectively controlled fish maturation and spawning through its effects on the hypothalamic-pituitary-gonadal (HPG) axis (Zohar \& Mylonas, 2001; Lim, 2016). In the short term, the treatment also causes ovulation and spermiation synchronization in farmed fish. By contrast, long-term effects, such as reproductive cycle regulation, can be induced by a controlled environment. Although these two contrasting treatments seem to act independently, together, they ultimately regulate fish maturation and spawning.

When fish process external information such as photoperiod or water temperature, they secrete gonadotropin-releasing hormone $(\mathrm{GnRH})$ in the hypothalamus, which stimulates the pituitary gland to release gonadotropin $(\mathrm{GtH})$. GtH stimulates the gonads and promotes the secretion of sex steroid hormones. Thus, plasma levels of sex steroid hormones provide important information about the fish's reproductive cycle and maturation (Tan-Fermin et al., 1997; Barcellos et al., 2001; Lee \& Yang, 2002; Manosroi et al., 2003). Estradiol-17ß $\left(E_{2}\right)$, a representative sex steroid hormone in female fish, induces the secretion of vitellogenin, a yolk protein in the liver. In general, the highest level of $E_{2}$ appears at yolk formation and before ovulation, after which the level decreases to its original concentration (Fostier et al., 1983; Kime, 1993; Silversand et al., 1993; Frantzen et al., 2004; Adebiyi et al., 2013). Testosterone (T) is a male sex steroid hormone (Tanaka et al., 1992; Nagaharna et al., 1995; Schulz \& Miura, 2002) that acts as a precursor to other sex steroid hormones such as 11-ketotestosterone (Young et al., 2005). The steroid 17a,20ßdihydroxy-4-pregnen-3-one (17a20 $\beta$ OHP) can induce the final maturation of oocytes in fish (Tokarz et al., 2015). In vertebrates, the hormone melatonin (M) is regularly synthesized and secreted by the pineal gland according to the day and night cycle of the environment. Melatonin is an indicator of the photoperiod and is secreted according to the circadian fluctuation, showing high levels at night (Falcon et al., 2010; Reiter, 1993). Recently, it was reported that melatonin not only plays a role in determining spawning timing in fish but also acts as an antioxidant in the control of oocyte maturation along the HPG axis (Maitra \& Hasan, 2016). It is generalized that changes in the photoperiod, which regulates the reproductive cycle of fish, cause changes in maturation-related hormones and melatonin, and that maturation and spawning are regulated according to these changes (Oliveira et al., 2011).

Starry flounder, Platichthys stellatus, is a fish that is widely distributed in the North Pacific Ocean from Korea, Japan, the Okhotsk Sea, and the Bering Sea to the Gulf of California (Nam et al., 2008). It belongs to the spring spawners and its spawning period is March to May in the waters of Korea (Lim et al., 2007). Recently, the demand for starry flounders has increased, and breeding companies have produced seeds using artificial insemination during the natural spawning season. However, the mortality rate of juvenile starry flounders increased when transferring the hatch to farms in summer as temperatures increased. Furthermore, female eggs do not naturally ovulate on farms for unknown reasons even though broodstocks are sufficiently matured. To solve these 
problems, the present study aims to accelerate the sexual maturation period of starry flounders by controlling the photoperiod and water temperature of their environment and by inducing final maturation and ovulation by injecting exogenous hormones following previous studies (Lim, 2016). In addition, we investigated whether accelerating the spawning period affects egg volume, egg quality, and sex steroid hormones levels in the plasma.

\section{Ethical statement}

\section{Materials and Methods}

All procedures were performed following the ethical treatment of animals and were approved by the Institutional Animal Care and Use Committee of Mokpo National University No. 1183 (December 17, 2013).

\section{Experimental fish and groups}

The experiments were conducted at the Marine Seed fish farm in Yeosu, Korea. We had two experimental groups: regulated photoperiod and regulated temperature experimental group (RPRT) and natural and water temperature experimental control group (NPNT). The starry flounders used in the RPRT group were 31 females with a total length of $43.4 \pm 0.4$ $\mathrm{cm}$ and a weight of $1728.6 \pm 206.1 \mathrm{~g}$ and 35 males with a total length of $34 \pm 0.7 \mathrm{~cm}$ and a weight of $617.3 \pm 20.7 \mathrm{~g}$. In the NPNT group, there were 49 females with a total length of $43.8 \pm 0.5 \mathrm{~cm}$ and a weight of $1467.3 \pm 113.3 \mathrm{~g}$ and 52 males with a total length of $33.1 \pm 0.3 \mathrm{~cm}$ and a weight of $560 \pm 14.5 \mathrm{~g}$.

Experimental conditions were established by modifying them in the previous study of the olive flounder (Paralichthys olivaceus) (Tsujigado et al., 1987), which is closely phylogenetic related to the species, and a preliminary experiment was conducted to determine the experimental conditions. Based on the preliminary experimental results, the condition of the photoperiod and water temperature regulation was established.

A 99\% light-shielding net (DIYdeco, Pocheon, South Korea) was installed in the RPRT group tank. The adjusted photoperiod and water temperature were designed as in a previous study (Kim and Hur, 1991) and natural photoperiod and water temperature. Beginning September 20, 2018, the natural daylight photoperiod was lowered by 10 minutes every 3 days, ending at a duration of 8 hours. The water temperature was lowered by $1^{\circ} \mathrm{C}$ every 3 days from September 20,2018 , until it reached $8^{\circ} \mathrm{C}$ and was then raised again for $1^{\circ} \mathrm{C}$ every 4 days until it reached $10^{\circ} \mathrm{C}$ (Figure 1).

The temperature was adjusted by installing a heat pump, a cooler, and a boiler. The NPNT control group was reared using the natural photoperiod and natural water temperature (Figure 1). In both experimental groups, a 25 ton $(5 \times 5 \times 1 \mathrm{~m})$ square tank was used as a breeding tank, and $1600 \%$ of the rearing water was changed every day. Dissolved oxygen was maintained above $7 \mathrm{ppm}$. Suhyup feed extruded pellets No. 7 (crude protein $54.0 \%$, crude fat $8.0 \%$, calcium $1.5 \%$, crude meal $14.0 \%$, crude fiber $3.0 \%$, and phosphorus 2.7\%; National Federation of Fisheries Cooperation Feed, Seoul, Korea) were supplied once a day at 3 p.m. 

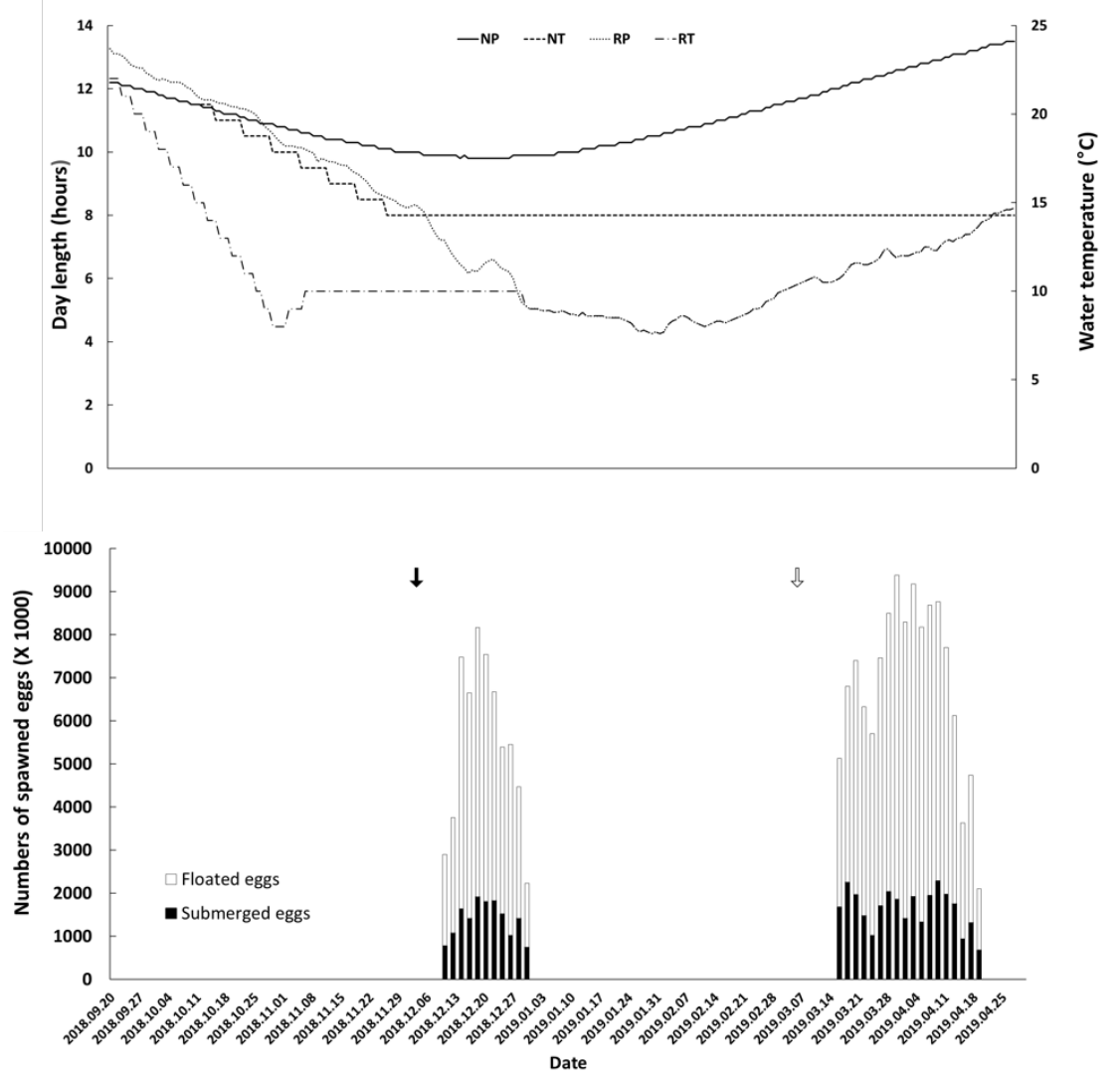

Figure 1 Day length, water temperature, and number of spawned eggs in the experimental groups during the experimental period. NP, natural photoperiod; NT, natural water temperature; RP, regulated photoperiod; RT, regulated water temperature; NPNT, natural photoperiod natural water temperature; RPRT, regulated photoperiod regulated water temperature. The white and black arrows indicate the timing of GnRHa pellet treatment in groups NPNT and RPRT, respectively.

\section{Hormonal treatment}

Each group induced early gonadal maturation by regulating the photoperiod and water temperature. After determining the maturation of the gonad visually referring to a previous study (Sanborn and Misitano, 1991), and then implanted hormones pellets. As a hormone for inducing spawning, commercially available Ovaplant (Syndel, Washington, USA) pellets containing sGnRHa as the main component were implanted into the dorsal muscle at a of $50 \mu \mathrm{g} / \mathrm{kg}$ concentration. Forty to sixty percent of the sGnRH is putatively released within 24 hours, with the remainder released over the next 7 to 21 days.

In RPRT, which induced gonadal maturation through photoperiod and water temperature regulation, sGnRH pellets were implanted on November 29, 2018, for final maturation and spawning. For NPNT, gonadal maturation began later than RPRT, and sGnRH pellets for final maturation and ovulation induction were implanted on March 4, 2019.

\section{Egg and sperm collection, and artificial insemination}

Each experimental group was anesthetized with $200 \mathrm{ppm}$ of ethyl 3-aminobenzoate methanesulfonate salt (Sigma, St. Louis, MO, USA), and eggs and milt were collected through abdominal compression. Eggs were harvested from the RPRT group once every 2 days from December 10, 2018, until the end of spawning and from the NPNT group once every 2 days from March 16, 2019, until the end of spawning. Collected eggs and milt were artificially inseminated, placed in a fertilized egg tank, and managed until hatching. Then, 
egg volume, floating rate, fertilization rate, and hatching rate measurements took place (Table 1). The floating rate was determined as the ratio of floating embryos among all fertilized eggs using a measuring cylinder after artificial insemination and egg washing. The fertilization rate was determined as the ratio between the number of embryos that developed after four-cell stages and the total number of floating eggs, using floating eggs that were randomly collected 4 hours after fertilization. The hatching rate was calculated by counting the number of hatched larvae against the total number of embryos.

Table 1 Egg volume, floating rate, fertilization rate, and hatching rate of the starry flounder Platichthys stellatus during the experimental period.

\begin{tabular}{ccc}
\hline & RPRT & NPNT \\
\hline \hline Egg volume $(\mathrm{mL} / \mathrm{kg} \mathrm{BW})$ & $103.0 \pm 11.2$ & $95.9 \pm 6.6$ \\
Floating rate $(\%)$ & $73.99 \pm 1.37$ & $75.32 \pm 1.21$ \\
Fertilization rate (\%) & $78.38 \pm 1.17$ & $79.54 \pm 0.96$ \\
Hatching rate $(\%)$ & $30.93 \pm 1.60$ & $31.25 \pm 1.64$
\end{tabular}

RPRT, regulated photoperiod regulated water temperature; NPNT, natural photoperiod natural water temperature.

\section{Blood sampling and sex steroid hormones analysis}

Blood was collected from the two experimental groups from October 25, 2018, to May 25,2019 , at 10 a.m. on the $25^{\text {th }}$ day of each month. Ten females were randomly selected and anesthetized, and blood was collected from the tail-end microvascular with a 23G syringe treated with heparin sodium. The collected blood was centrifuged $(10,000 \mathrm{rpm}, 10$ $\mathrm{min}$ ) to separate the plasma. Only the supernatant was transferred into a $1.5 \mathrm{~mL}$ tube and stored in an ultra-low temperature freezer at $-80^{\circ} \mathrm{C}$ until analysis.

Plasma testosterone $(T)$ and estradiol-17 $\left(E_{2}\right)$ concentrations were measured with the fish testosterone ELISA kit (CSB-E17554Fh, CUSABIO, Houston, TX, USA) and fish estradiol ELISA kit (CSB-E13017Fh, CUSABIO). 17a,20ß-dihydroxy-4-pregnen-3-one (17a,20 $\mathrm{OHP}$ ) and melatonin (M) were analyzed with the fish $17 \mathrm{a}, 20 \beta$-dihydroxy progesterone (17a,20ß-OH-PROG) ELISA kit (MBS2602842, MyBiosource, San Diego, CA, USA) and fish melatonin ELISA kit (MBS166231, MyBiosource).

\section{Statistics analysis}

For each experiment, the mean and standard error were calculated, and a one-way ANOVA, Duncan multiple tests, and t-test were performed using the SPSS-statistics program (version 24) to test for significant differences between measurements $(P<0.05)$.

\section{Spawning volume and egg quality}

\section{Results}

Eggs were collected every 2 days from the RPRT group, beginning on December 10, 2018, and 11 times. For the control NPNT group, eggs were available from March 16, 2019, and collected 18 times at 2-day intervals (Figure 1). The average number of eggs per 1 $\mathrm{kg}$ body weight was $103.0 \pm 11.2 \mathrm{~mL}$ in the RPRT group and $95.9 \pm 6.6 \mathrm{~mL}$ in the NPNT group; this difference was insignificant. The floating rates of the RPRT and NPNT groups were $73.99 \pm 1.37 \%$ and $75.32 \pm 1.21 \%$, respectively, with no significant difference observed between the two groups. The fertilization and hatching rates of the two experimental groups also showed no significant differences (Table 1).

\section{Changes in plasma levels of sex steroid hormones and melatonin}


In the RPRT group, the T level in the plasma was $11.04 \pm 0.99 \mathrm{ng} / \mathrm{mL}$ in October and showed the highest level in November at $14.40 \pm 0.82 \mathrm{ng} / \mathrm{mL}$. After that, the plasma $T$ level gradually decreased, reaching its lowest at $1.70 \pm 0.27 \mathrm{ng} / \mathrm{mL}$ in March and increasing again (Figure 2). In the control group, the T level in the plasma decreased until December, then peaked at $17.57 \pm 0.75 \mathrm{ng} / \mathrm{mL}$ in January, followed by a gradual decrease. The $T$ concentration in the plasma showed a significant difference between the two experimental groups from November to April (Figure 2).

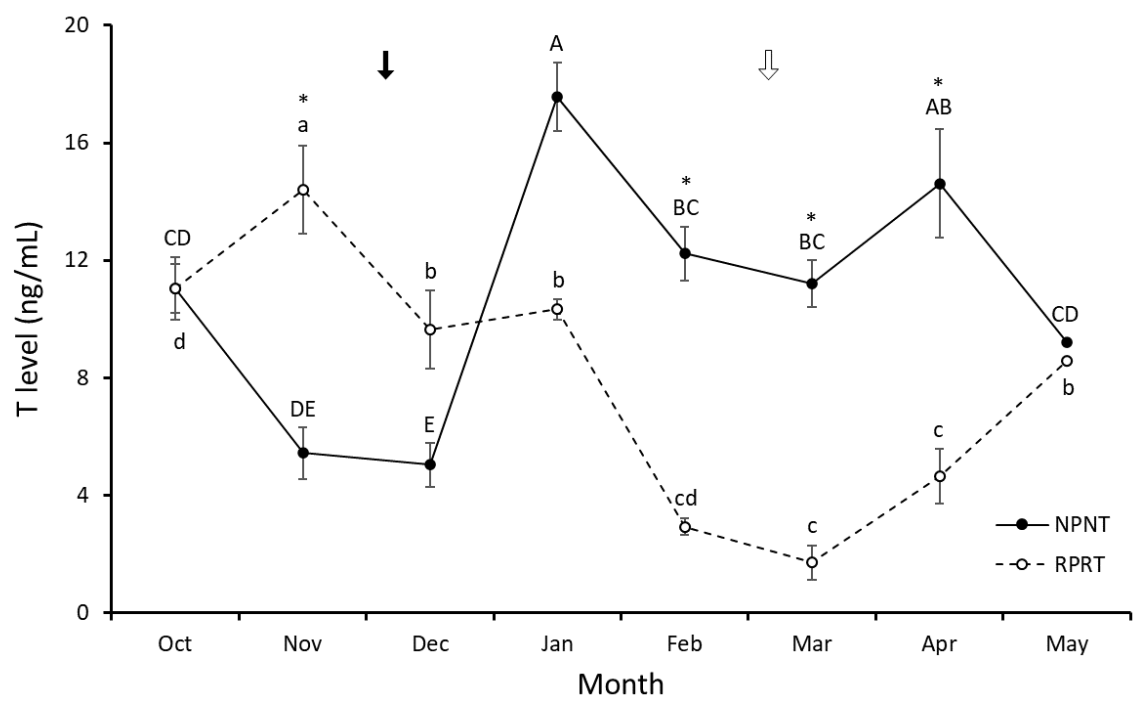

Figure 2 Changes in the testosterone $(\mathrm{T})$ plasma concentration in the starry flounder Platichthys stellatus during the experimental period. Letter labels (uppercase for group NPNT, lowercase for group RPRT) indicate significant differences between sampling times $(P<0.05)$. Asterisks indicate significant differences between groups NPNT and RPRT at that sampling time $(P<0.05)$. The black and white arrows indicate the timing of GnRHa pellet treatment in groups RPRT and NPNT, respectively. NPNT, natural photoperiod natural water temperature; RPRT, regulated photoperiod regulated water temperature.

In October, the level of $E_{2}$ in the plasma was $1.65 \pm 0.01 \mathrm{ng} / \mathrm{mL}$ in group RPRT, which remained stable until December and reached its lowest concentration at $1.27 \pm 0.08 \mathrm{ng} / \mathrm{mL}$ in January. The level of $E_{2}$ in the plasma was $1.65 \pm 0.01 \mathrm{ng} / \mathrm{mL}$ in October in group RPRT, which remained stable until December, and then reached its lowest level at $1.27 \pm 0.08$ $\mathrm{ng} / \mathrm{mL}$ in January. However, it increased again from January on and remained at its initial concentration from March to May (Figure 3). The $E_{2}$ level in the plasma of group NPNT remained unchanged until January, showed its lowest level at $1.31 \pm 0.07 \mathrm{ng} / \mathrm{mL}$ in February, and recovered to its initial level in March, at which it stayed until May (Figure 3). The plasma $17 a 20 \beta$ OHP value of group RPRT increased rapidly from $7.11 \pm 1.54 \mathrm{ng} / \mathrm{mL}$ in October to $16.38 \pm 0.31 \mathrm{ng} / \mathrm{mL}$ in November and then gradually decreased (Figure 4). In group NPNT, the plasma 17a20 $\beta$ OHP level increased until January, showing its highest level at $15.81 \pm 0.26 \mathrm{ng} / \mathrm{mL}$, and then decreased slightly (Figure 4). The level of $\mathrm{M}$ in the plasma of group RPRT increased to $9.22 \pm 2.25 \mathrm{ng} / \mathrm{mL}$ in October and continued to increase every month except January; the highest value was $37.95 \pm 1.00 \mathrm{ng} / \mathrm{mL}$ in May (Figure 5). The control group NPNT followed the same pattern, with an increase until March followed by a decrease in April and May. The level of $M$ in the plasma showed a significant difference between the two experimental groups from November to May, excluding March (Figure 5). 


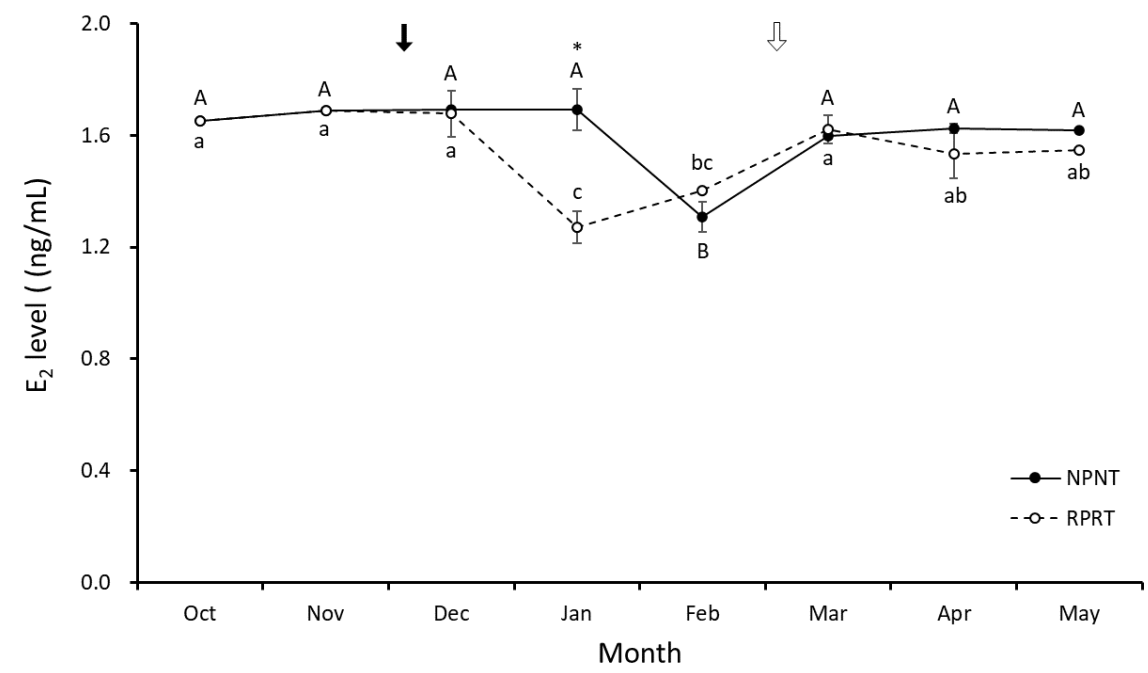

Figure 3 Changes in the estradiol $\left(E_{2}\right)$ plasma concentration in the starry flounder Platichthys stellatus during the experimental period. Letter labels (uppercase for group NPNT, lowercase for group RPRT) indicate significant differences between sampling times $(P<0.05)$. Asterisks indicate significant differences between groups NPNT and RPRT at that sampling time $(P<0.05)$. The black and white arrows indicate the timing of GnRHa pellet treatment in groups RPRT and NPNT, respectively. NPNT, natural photoperiod natural water temperature; RPRT, regulated photoperiod regulated water temperature.

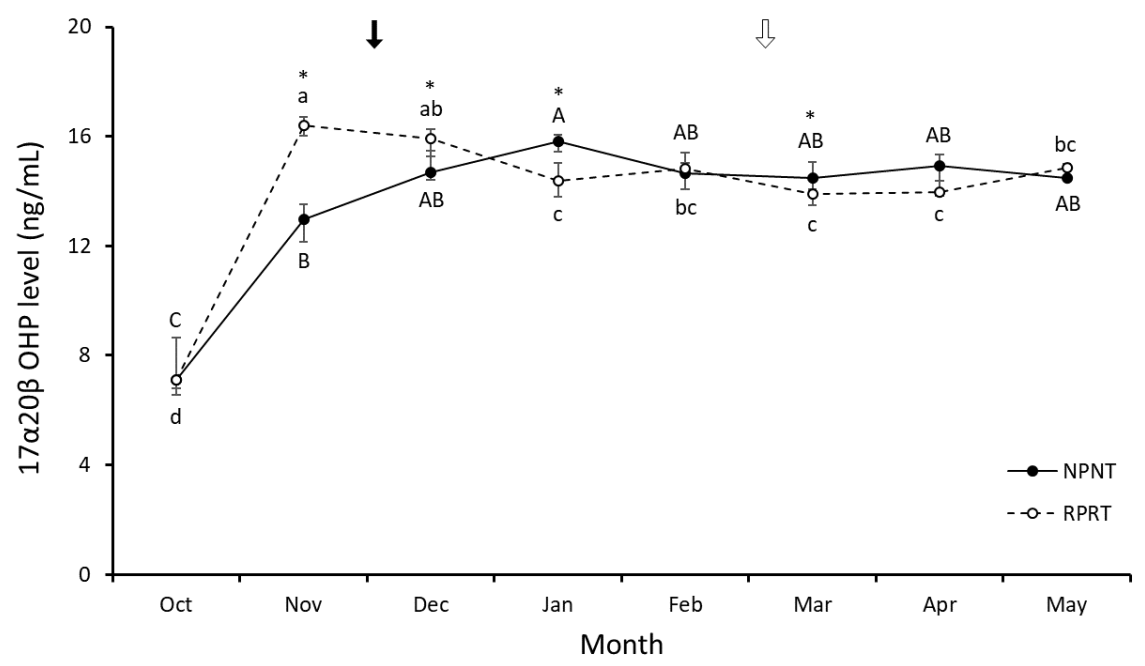

Figure 4 Changes in the $17 a, 20 \beta$-dihydroxy progesterone (17a20 $\beta$ OHP) plasma concentration in the starry flounder Platichthys stellatus during the experimental period. Letter labels (uppercase for group NPNT, lowercase for group RPRT) indicate significant differences between sampling times $(P<0.05)$. Asterisks indicate significant differences between groups NPNT and RPRT at that sampling time $(P<0.05)$. The black and white arrows indicate the timing of GnRHa pellet treatment in groups RPRT and NPNT, respectively. NPNT, natural photoperiod natural water temperature; RPRT, regulated photoperiod regulated water temperature. 


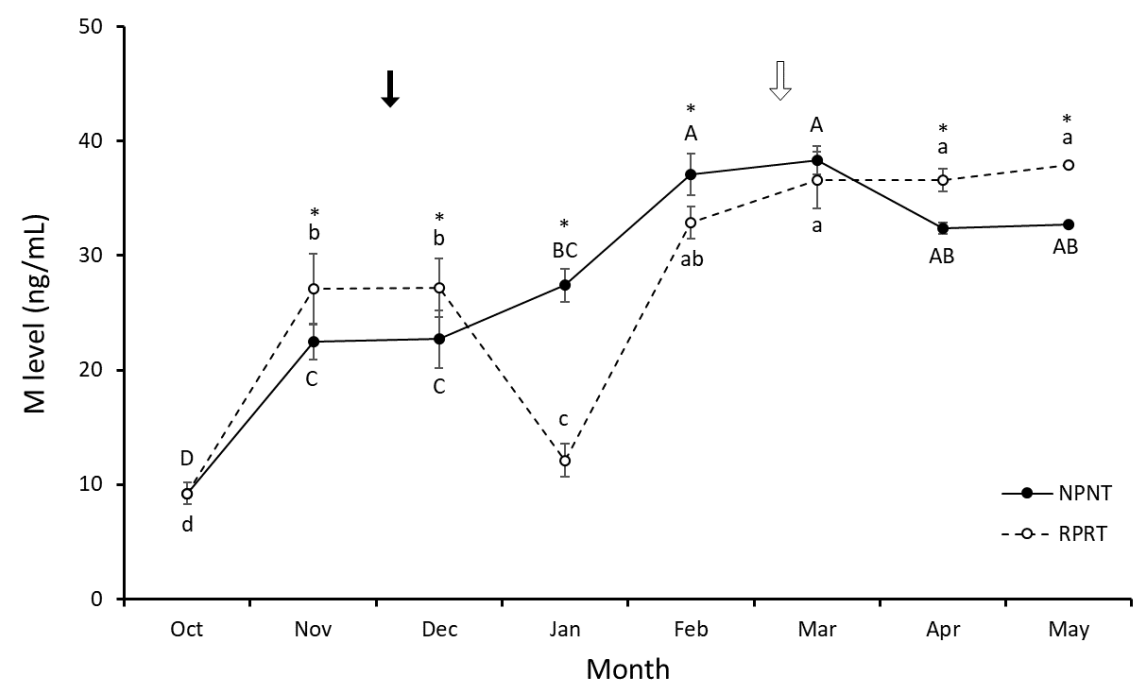

Figure 5 Changes in the melatonin plasma concentration in the starry flounder Platichthys stellatus during the experimental period. Letter labels (uppercase for group NPNT, lowercase for group RPRT) indicate significant differences between sampling times $(P<0.05)$. Asterisks indicate significant differences between groups NPNT and RPRT at that sampling time $(P<0.05)$. The black and white arrows indicate the timing of GnRHa pellet treatment in groups RPRT and NPNT, respectively. NPNT, natural photoperiod natural water temperature; RPRT, regulated photoperiod regulated water temperature.

\section{Discussion}

This study was conducted on a commercial scale that allowed to manage starry flounder broodstocks in a large tank (width and length, $5 \mathrm{~m}$ ) to produce and sell seeds and fertilized eggs. Although the spawning timing of starry flounders raised indoors in March or April (Lim et al., 2007), in this study, it was possible to induce spawning in December, three months ahead of natural conditions adjusting the photoperiod and water temperature. There was no significant difference in spawning number, fertilization, hatching rate, or floating rate in the two experimental groups. It means that manipulation of the environment can control the spawning period without affecting the spawning number or egg quality. Additionally, it can be the selling larger sizes of fish at the time of selling period, which is significant for the industrial application of this approach. Many previous studies that used photoperiod and water temperature to control the spawning period did not investigate spawning number and egg quality (Wang et al., 2010; Okuzawa et al., 1989; Hansen et al., 2001). Therefore, our study shows the effect of spawning period control on egg quality for the first time.

Egg quality is influenced by various of factors such as fish health, nutritional status, male to female ratio, breeding environment, and female broodstock age. Therefore, it cannot be excluded that the variation in spawning season by environmental control does not affect the egg quality of starry flounders (Bromage, 1995). However, because broodstock breeding requires more careful attention and effort than large-scale rearing of edible fish, it is thought that environmental control does not have a significant effect on egg quality if only spawning is regulated, and other breeding conditions are appropriate. In hatcheries, egg quality is an essential factor that can determine the success of seed production; systematic research on this will be needed in the future.

According to a previous study on the reproductive cycle and changes in sex steroid hormones of starry flounders, $E_{2}$ levels increased before spawning. They then declined with spawning, and $T$ levels peaked during spawning and then gradually decreased (Hwang et al., 2012). However, in our study, the T levels of both groups tended to fluctuate one or 
two months before spawning, and the $E_{2}$ levels were not found to be associated with spawning. There could be many reasons why this study differs from previous studies (Lim, 2016; Hwang et al., 2012). First, in our study, exogenous GnRHa pellets were implanted at a $50 \mu \mathrm{g} / \mathrm{kg}$ concentration to both experimental groups to induce ovulation. GnRHa treatment may have affected plasma levels of sex steroids in starry flounders. Second, the starry flounders used in the experiment have a different origin. Wild-caught fish were used in a previous study (Hwang et al., 2012), while farm-raised fish were used in the present study. Third, since starry flounder is a multi-spawning fish that spawns several times during the spawning period, there are several oocyte developments stages in the ovary, depending on the individual and, therefore, the plasma levels of steroids can vary depending on the ovary developmental stage.

$17 \mathrm{a} 20 \beta \mathrm{OHP}$ is involved in the final maturation and ovulation of oocytes (Zohar \& Mylonas, 2001; Lim, 2016; Pankhurst \& Thomas, 1998). Lim (2016) reported that GnRHa treatment increased plasma levels of $17 a 20 \beta$ OHP concerning reproductive traits in female starry flounders. In the present study, both the RPRT and NPNT groups showed rapidly increased $17 a 20 \beta$ OHP levels one or two months before the start of spawning. This result is consistent with a previous study by Heidari et al. (2018).

The spawning season of fish is affected by the photoperiod (Heidari et al., 2018; Taranger et al., 1999), and several studies have reported that melatonin has a potential effect on sexual maturity (Maitra \& Hasan, 2016; Singh et al., 2012). A study on plasma $M$ levels concerning photoperiod and water temperature in Senegal sole (Solea senegalensis) showed significant differences in M levels, depending on photoperiod and seasonal water temperature. M levels measured during the day stayed constant throughout the year (Vera et al., 2007). The circadian hormone melatonin is secreted at night in all vertebrates (Falcón et al., 1992). Therefore, we believe that the plasma sample collection time affected plasma $M$ levels in the two groups in our study, which may explain the lack of significant difference between them.

In conclusion, female starry flounders were considered egg quality similar to natural conditions when spawning was controlled by photoperiod and water temperature. We also demonstrated that the secretion period of plasma steroid hormones could be accelerated, successfully triggering early spawning. These results will have a high impact on the future of starry flounder hatcheries.

\section{Acknowledgements}

This study was supported by the Korea Institute of Marine Science \& Technology Promotion, South Korea (Assignment No. 20180373). The research part of the project is titled "Establishing a foundation for the year-round production of flatfish eggs and improving productivity".

\section{References}

Adebiyi F. A., Siraj S. S., Harmin S. A., Christianus A., 2013. Plasma sex steroid hormonal profile and gonad histology during the annual reproductive cycle of river catfish (Hemibagrus nemurus) (Valenciennes, 1840) in captivity. Fish Physiology and Biochemistry, 39, 547-557. https://doi.org/10.1007/s10695-012-9718-x

Akhoundian, M., Salamat, N., Savari, A., Movahedinia, A., Salari, M. A., 2020. Influence of photoperiod and temperature manipulation on gonadal development and spawning in Caspian roach (Rutilus rutilus caspicus): Implications for artificial propagation. Aquaculture Research, 51(4), 1623-1642. https://doi.org/10.1111/are.14509

Barcellos L. J. G., Wassermann F. G., Scott A. P., Woehl V.M., Quevedo R.M., Istvanittzes I., Krieger M.H., Lulhier F., 2001. Steroid profiles in cultured female jundia, the siluridae rhamdia quelen (Quoy and gaimard, pisces, teleostei) during the first reproductive cycle. General and Comparative Endocrinology, 121, 325-332. https://doi.org/10.1006/gcen.2001.7603

Bromage, N., 1995. Broodstock management and egg and larval quality. Broodstock Management and Seed Quality-General Considerations, 1-24. 
Cyr, B. A. D., Tveiten, H., Maltais, D., Vandenberg, G. W., Le François, N. R., 2018. Photoperiod manipulation for the reproductive management of captive wolffish populations: Anarhichas minor and A. lupus. Aquaculture International, 26(4), 1051-1065. https://doi.org/10.1007/s10499-018-0267-x

Falcon, J., Migaud, H., Munoz-Cueto, J. A., Carrillo, M., 2010. Current knowledge on the melatonin system in teleost fish. General and comparative endocrinology, 165(3), 469482. https://doi.org/10.1016/j.ygcen.2009.04.026

Fostier, A., Jalabert, B., Billard, R., Breton, B., Zohar, Y., 1983. 7 The Gonadal Steroids. Fish physiology, 9, 277-372. https://doi.org/10.1016/S1546-5098(08)60291-5

Frantzen, M., Arnesen, A. M., Damsgård, B., Tveiten, H., Johnsen, H. K., 2004. Effects of photoperiod on sex steroids and gonad maturation in Arctic charr. Aquaculture, 240(1-4), 561-574. https://doi.org/10.1016/j.aquaculture.2004.07.013

Hansen, T., Karlsen, Ø., Taranger, G. L., Hemre, G. I., Holm, J. C., Kjesbu, O. S., 2001. Growth, gonadal development, and spawning time of Atlantic cod (Gadus morhua) reared under different photoperiods. Aquaculture, 203(1-2), 51-67. https://doi.org/10.1016/S0044-8486(01)00610-X

Heidari, B., Roozati, S. A., Yavari, L., 2018. Changes in plasma levels of steroid hormones during oocyte development of Caspian Kutum (Rutilus frisii kutum, Kamensky, 1901). Animal Reproduction, 7(4), 373-381.

Hwang, I. J., Lee, J. B., Choi, S. J., Kim, S. K., Cha, H. K., Oh, T. Y., Baek, H. J., 2012. Reproductive capacity in starry flounder Platichthys stellatus from Uljin marine ranching area, Korea. Korean Journal of Fisheries and Aquatic Sciences, 45(3), 253-261. https://doi.org/10.5657/KFAS.2012.0253

Imsland, A. K., Hangstad, T. A., Jonassen, T. M., Stefansson, S. O., Nilsen, T. O., Hovgaard, P., Reynolds, P., 2019. The use of photoperiods to provide year-round spawning in lumpfish Cyclopterus lumpus. Comparative Biochemistry and Physiology Part A: Molecular \& Integrative Physiology, 228, 62-70. https://doi.org/10.1016/j.cbpa.2018.11.004

Kim, Y. and Hur, S. B., 1991. Spawning inducement of flounder, Paralichthys olivaceus by the control of water temperature and photoperiod. Journal of Aquaculture, 4(2), 85-95. Kime, D. E., 1993. 'Classical' and 'non-classical' reproductive steroids in fish. Reviews in Fish Biology and Fisheries, 3(2), 160-180. https://doi.org/10.1007/BF00045230

Lee, W. K. and Yang, S. W., 2002. Relationship between ovarian development and serum levels of gonadal steroid hormones, and induction of oocyte maturation and ovulation in the cultured female Korean spotted sea bass Lateolabrax maculatus (Jeom-nong-eo). Aquaculture, 207(1-2), 169-183. https://doi.org/10.1016/S0044-8486(01)00728-1

Lim, H. K., Byun, S. G., Lee, J. H., Park, S. U., Kim, Y. C., Han, H. K., Lee, B. Y., 2007. Sexual maturity and reproductive cycle of starry flounder Platichthys stellatus cultured in indoor tank. Journal of Aquaculture, 20(4), 212-218.

Lim, H. K., 2016. Effect of exogenous hormones on ovulation and gonadal steroid plasma levels in starry flounder, Platichthys stellatus. Aquaculture International, 24(4), 10611071. https://doi.org/10.1007/s10499-016-9971-6

Lundova, K., Matousek, J., Prokesova, M., Vanina, T., Sebesta, R., Urban, J., Stejskal, V., 2019. The effects of a prolonged photoperiod and light source on growth, sexual maturation, fin condition, and vulnerability to fungal disease in brook trout Salvelinus fontinalis. Aquaculture Research, 50(1), 256-267. https://doi.org/10.1111/are.13891

Maitra, S. K. and Hasan, K. N., 2016. The role of melatonin as a hormone and an antioxidant in the control of fish reproduction. Frontiers in endocrinology, 7, 38. https://doi.org/10.3389/fendo.2016.00038

Manosroi, A., Meng-Umphan, K., Manosroi, J., 2003. Annual sex hormonal profiles, gonad development and age determination of the Mekong giant catfish (Pangasianodon gigas, Chevey). Aquaculture Research, 34(15), 1379-1385. https://doi.org/10.1111/j.1365-2109.2003.00955.x 
Nagahama, Y., Yoshikuni, M., Yamashita, M., Tokumoto, T., Katsu, Y., 1995. 4 Regulation of oocyte growth and maturation in fish. Current topics in developmental biology, 30, 103-145. https://doi.org/10.1016/S0070-2153(08)60565-7

Nam, M. M., Byun, S. G., Lee, B. I., Lee, J. H., Kim, Y. C., 2008. Morphological characteristics of the hybrids of female flounder Paralichthys olivaceus and male starry flounder Platichthys stellatus. Korean Journal of Ichthyology, 20(4), 285-290.

Norberg, B., Brown, C. L., Halldorsson, O., Stensland, K., Björnsson, B. T., 2004. Photoperiod regulates the timing of sexual maturation, spawning, sex steroid and thyroid hormone profiles in the Atlantic cod (Gadus morhua). Aquaculture, 229(1-4), 451-467. https://doi.org/10.1016/S0044-8486(03)00393-4

Okuzawa, K., Furukawa, K., Aida, K., Hanyu, I., 1989. Effects of photoperiod and temperature on gonadal maturation, and plasma steroid and gonadotropin levels in a cyprinid fish, the honmoroko Gnathopogon caerulescens. General and comparative endocrinology, 75(1), 139-147. https://doi.org/10.1016/0016-6480(89)90019-1

Oliveira, C., Mañanós, E., Ramos, J., Sánchez-Vázquez, F. J., 2011. Impact of photoperiod manipulation on day/night changes in melatonin, sex steroids and vitellogenin plasma levels and spawning rhythms in Senegal sole, Solea senegalensis. Comparative Biochemistry and Physiology Part A: Molecular \& Integrative Physiology, 159(3), 291-295. https://doi.org/10.1016/j.cbpa.2011.03.025

Pankhurst, N. W. and Thomas, P. M., 1998. Maintenance at elevated temperature delays the steroidogenic and ovulatory responsiveness of rainbow trout Oncorhynchus mykiss to luteinizing hormone releasing hormone analogue. Aquaculture, 166(1-2), 163177. https://doi.org/10.1016/S0044-8486(98)00284-1

Planas, M., Quintas, P., Chamorro, A., 2013. Maturation of Hippocampus guttulatus and Hippocampus hippocampus females by manipulation of temperature and photoperiod regimes. Aquaculture, 388, 147-152. https://doi.org/10.1016/j.aquaculture.2013.01.030 Reiter, R. J., 1993. The melatonin rhythm: both a clock and a calendar. Experientia, 49(8), 654-664. https://doi.org/10.1007/BF01923947

Sanborn, H. R. and Misitano, D. A., 1991. Hormonally induced spawning of English sole (Parophrys vetulus Girard). Journal of applied ichthyology, 7(1), 15-25. https://doi.org/10.1111/j.1439-0426.1991.tb00590.x

Schulz, R. W. and Miura, T., 2002. Spermatogenesis and its endocrine regulation. Fish physiology and biochemistry, 26(1), 43-56. https://doi.org/10.1023/A:1023303427191

Silversand, C., Hyllner, S. J., Haux, C., 1993. Isolation, immunochemical detection, and observations of the instability of vitellogenin from four teleosts. Journal of Experimental Zoology, 267(6), 587-597. https://doi.org/10.1002/jez.1402670606

Singh, R., Singh, A. K., Tripathi, M., 2012. Melatonin induced changes in specific growth rate, gonadal maturity, lipid and protein production in Nile tilapia Oreochromis niloticus (Linnaeus 1758). Asian-Australasian journal of animal sciences, 25(1), 37. https://doi.org/10.5713/ajas.2011.11139

Tanaka, M., Telecky, T. M., Fukada, S., Adachi, S., Chen, S., Nagahama, Y., 1992. Cloning and sequence analysis of the cDNA encoding P-450 aromatase (P450arom) from a rainbow trout (Oncorhynchus mykiss) ovary; relationship between the amount of P450arom mRNA and the production of oestradiol-17 $\beta$ in the ovary. Journal of molecular endocrinology, 8(1), 53-61. https://doi.org/10.1677/jme.0.0080053

Tan-Fermin, J. D., Ijiri, S., Ueda, H., Adachi, S., Yamauchi, K., 1997. Ovarian development and serum steroid hormone profiles in hatchery-bred female catfish Clarias macrocephalus (Gunther) during an annual reproductive cycle. Fisheries science, 63(6), 867-872. https://doi.org/10.2331/fishsci.63.867

Taranger, G. L., Haux, C., Hansen, T., Stefansson, S. O., Björnsson, B. T., Walther, B. T., Kryvi, H., 1999. Mechanisms underlying photoperiodic effects on age at sexual maturity in Atlantic salmon, Salmo salar. Aquaculture, 177(1-4), 47-60. https://doi.org/10.1016/S0044-8486(99)00068-X 
Tokarz, J., Möller, G., de Angelis, M. H., Adamski, J., 2015. Steroids in teleost fishes: a functional point of view. Steroids, 103, 123-144. https://doi.org/10.1016/j.steroids.2015.06.011

Tsujigado, A., Yamakawa, T., Matsuda, H., Kamiya, N., 1987. Advanced spawning of the flounder, Paralichthys olivaceus, in an indoor tank with combined manipulation of water temperature and photoperiod. Bulletin of the Fisheries Research Institute of Mie (Japan).

Vera, L. M., De Oliveira, C., López-Olmeda, J. F., Ramos, J., Mananos, E., Madrid, J. A., Sánchez-Vázquez, F. J., 2007. Seasonal and daily plasma melatonin rhythms and reproduction in Senegal sole kept under natural photoperiod and natural or controlled water temperature. Journal of pineal research, 43(1), 50-55. https://doi.org/10.1111/j.1600-079X.2007.00442.x

Wang, N., Teletchea, F., Kestemont, P., Milla, S., Fontaine, P., 2010. Photothermal control of the reproductive cycle in temperate fishes. Reviews in Aquaculture, 2(4), 209222. https://doi.org/10.1111/j.1753-5131.2010.01037.x

Young, G., Kusakabe, M., Nakamura, I., Lokman, P. M., Goetz, F. W., 2005. Gonadal steroidogenesis in teleost fish. Molecular aspects of fish and marine biology, 2, 155-223.

Zohar, Y. and Mylonas, C. C., 2001. Endocrine manipulations of spawning in cultured fish: from hormones to genes. Reproductive biotechnology in Finfish aquaculture, Elsevier, 99-136. https://doi.org/10.1016/B978-0-444-50913-0.50009-6. 